\title{
A democracia racial como um projeto de planificação social no pensamento de Guerreiro Ramos ${ }^{1}$
}

\section{Nikolas Pallisser Silva ${ }^{2}$}

\section{Alan Caldas ${ }^{3}$}
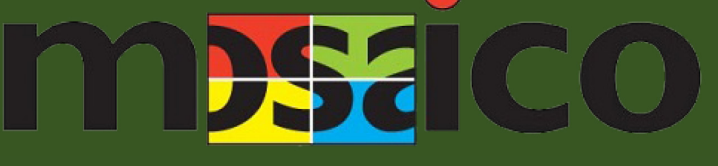
Resumo: O objetivo deste artigo é investigar o projeto político gerado em torno da democracia racial pela intelligentsia negra dos anos de 1940 e 1950, com foco na perspectiva de Guerreiro Ramos. Mostramos a partir de que perspectiva esse projeto foi desenvolvido, para quem ele se dirigia, quais suas razões sociológicas e qual sua legitimidade no contexto brasileiro. Em seguida, mostramos como ele pretendia atuar na canalização das irracionalidades produzidas pela mudança da estrutura social de uma ordem escravocrata e patrimonial para uma ordem competitiva e racionalburocrática. Por fim, encerramos indicando ações do Teatro Experimental do Negro que concretamente colocavam em prática esse projeto.

Palavras-chave: Democracia racial, Guerreiro Ramos, Movimentos negros.

Abstract: The object of this article is to investigate the political project generated around racial democracy by the black intelligentsia of the 1940s and 1950s, focusing on Guerreiro Ramos' perspective. We show from which perspective this project was developed, to whom it was addressed, what are its sociological reasons, and what is its legitimacy in the Brazilian context. Then we show how he intended to act in channeling the irrationalities produced by changing the social structure from a slave and patrimonial order to a competitive and rational-bureaucratic order. Finally, we end by indicating actions by Teatro Experimental do Negro that concretely put this project into practice.

Keywords: Racial democracy, Guerreiro Ramos, Black movements. 


\section{Introdução}

A tese que defenderemos neste trabalho é a de que a democracia racial, tal qual defendida por Guerreiro Ramos no final dos anos de 1940 e início dos anos 1950, no interior dos movimentos negros, constituiu um projeto de planificação social democrática da sociedade.

Para sustentar tal tese, vamos apresentar brevemente o contexto de discussão da democracia racial nos anos 1940 e 1950, com destaque para a posição dos movimentos negros inseridos nesse debate. Em seguida, apresentaremos de quem partia esse projeto de democracia racial, a quem se destinava, com que razões sociológicas se colocava e com qual legitimidade. Além disso, explicaremos em que consistia tal projeto de maneira geral e específica, exemplificando-o pelas ações dos intelectuais do Teatro Experimental do Negro (TEN). Para tanto, cabe uma breve inserção do leitor nesse universo.

Nos anos de 1940 e 1950, com a vitória dos Aliados na Segunda Guerra Mundial, a democracia tornou-se, por um lado, uma noção fundamental do ideário público e das práticas políticas; por outro lado, o racismo perdeu sua legitimidade científica dando espaço para que novos paradigmas de pesquisa se tornassem hegemônicos, como o culturalismo desenvolvido nas universidades dos Estados Unidos. Esses fatores constituíram um ambiente propício para que a ideia de democracia racial florescesse.

A ideia de que o Brasil seria uma espécie de paraíso racial datava, pelo menos, das campanhas abolicionistas. Dessa forma, desde o final do século XIX e mais intensamente nas primeiras décadas do século $X X$, podemos notar que a ideia do Brasil como paraíso racial já existia no imaginário de brasileiros, norte-americanos e europeus. Diversos viajantes negros norte-americanos que passaram pelo Brasil apontaram para o caráter relativamente positivo das relações raciais no país (ANDREWS, 2017).

Militantes antirracistas, como Frederick Douglass, usavam do contraste entre as relações raciais no Brasil e nos EUA para desnaturalizar estas últimas, tentando mostrar a existência de outras possibilidades de convívio racial. Nessa ideia de paraíso racial estariam juntas as noções de ausência de barreiras à ascensão social, a existência de uma história de relações escravocratas mais amenas e pouco ou nenhum preconceito contra o negro (GUIMARÃES, 2001; 2009). 
A mudança do ideário do paraíso racial para o da democracia racial coincidiu com a passagem do paradigma da raça para o da cultura e também com o protagonismo do TEN nas lutas antirracistas no país. Esse novo paradigma trouxe uma vantagem para os movimentos negros, já que a partir dele os supostos atrasos da população negra deixavam de ser devidos a essencialismos biológicos e se tornavam resultantes de processos de socialização que poderiam ser alterados. Isso possibilitou um certo consenso entre os intelectuais do TEN e intelectuais brancos tradicionais acerca de alguns pontos chave para a interpretação das relações raciais (GUIMARÃES, 2001).

No Brasil, um dos intelectuais pioneiros que contribuíram para a transição do paradigma racialista para o culturalista foi Gilberto Freyre. Ele também seria um dos responsáveis pela transformação da ideia de paraíso racial para a de democracia racial. A noção de democracia racial é atribuída à interpretação que Gilberto Freyre faz do Brasil Colônia, sobretudo em seus livros Casa Grande \& Senzala (1933) e Sobrados e Mucambos (1936). Tal compreensão defendia que as relações entre senhores e escravos, bem como, posteriormente, entre brancos e negros, teriam sido harmônicas, nas quais o conflito estaria quase que totalmente ausente (HASENBALG, 1979; GUIMARÃES, 2001; 2009). Assim, este amálgama das raças ou mestiçagem, para Freyre, proporcionou o que Carvalho (2008) chamou de equilíbrio de antagonismos, isto é, relações simétricas entre polos opostos: senhor e escravo, branco e negro, casa-grande e senzala etc.

Outro aspecto importante do contexto brasileiro a ser frisado é a maneira pela qual a miscigenação teria ocorrido com o objetivo de clareamento biológico e cultural da população brasileira, ou seja, como uma prática social voltada para o ideal de branqueamento. Se no pensamento de Freyre houve uma tentativa - não muito exitosa - de desassociar raça do plano da biologia, levando a discussão sobre a identidade brasileira para o plano da cultura, para a elite brasileira do final do século XIX e início do XX, a ideologia do branqueamento possuía foros de legitimidade científica (SKIDMORE, 1976). Aliás, a excessiva valorização da colonização e da cultura portuguesa por Gilberto Freyre não deixava de ser uma forma de continuidade do mito da branquitude (RAMOS, 1956a, 1956b).

É neste contexto que o TEN será um dos movimentos negros que buscará contrapor a narrativa submissa nesta versão da democracia racial e, de forma prática, buscará a mobilidade ascensional da população negra. Vale lembrar que antes da 
criação do TEN já haviam organizações com características diversas que reivindicavam melhorias para a população negra, como a Frente Negra Brasileira (FNB) na década de 30.

O Teatro Experimental do Negro foi criado e coordenado pelo militante e intelectual negro Abdias do Nascimento, em 1944, na cidade do Rio de Janeiro. Além de preparar atores e atrizes negros e apresentar peças teatrais, a organização proporcionava cursos de alfabetização, realizava congressos, pesquisas científicas, produzia o periódico Quilombo: vida, problemas e aspirações do negro, entre outras atividades.

Essa iniciativa surgiu após uma viagem de Nascimento, acompanhado de amigos, por alguns países da América do Sul. Foi em Lima (no Peru), ao ver o ator branco Hugo D'Evieri pintado de preto, interpretando o papel do imperador Jones na peça homônima de Eugene O'Neill, que o intelectual se chocou profundamente e decidiu que quando retornasse ao Brasil fundaria um teatro negro, o que ocorreu em 1944. Entre os partícipes da instituição, destacamos os nomes de Ruth de Souza, importante atriz brasileira; Arinda Serafim, atriz e empregada doméstica que ajudou a fundar o TEN; Ironides Rodrigues, escritor, crítico literário e responsável pela tradução de textos do francês para o português; Solano Trindade, pesquisador e ativista ligado ao Partido Comunista do Brasil (PCB) e Guerreiro Ramos, que, dentre outras funções, coordenou o Instituto Nacional do Negro (INN), um departamento de pesquisas e estudos do TEN (NASCIMENTO, A., 2004; MACEDO, 2005; NASCIMENTO, E., 2014).

Alberto Guerreiro Ramos (1915-1982) nasceu no interior da Bahia, numa família negra de classe média baixa. De meados dos anos 1930 até o início de 1940, dedicou-se à poesia e escreveu ensaios para importantes jornais de Salvador e do Rio de Janeiro. Em 1942, bacharelou-se em Ciências Sociais pela Faculdade Nacional de Filosofia (FNFi) e, no ano seguinte, em Direito pela Faculdade Nacional de Direito (FND), ambas instituições ligadas à Universidade do Brasil. Foi professor do Departamento Nacional da Criança (DNCr) de 1943 a 1948 e trabalhou no Departamento Administrativo do Serviço Público de 1943 até o início dos anos 1950, no qual dirigiu a seção de crítica da Revista do Serviço Público, contribuindo para a divulgação de sociólogos como Max Weber e Karl Mannheim no ambiente intelectual brasileiro. 
Desde 1948 até 1956, esteve ligado ao Teatro Experimental do Negro, atuando na organização de congressos e na direção do INN, órgão ligado ao TEN e responsável por pesquisas sobre as populações negras, função na qual desenvolveu práticas pioneiras de grupoterapia e sociodrama. Nas décadas de 1950 e 1960, foi um dos principais intelectuais públicos do Brasil, trabalhou na Casa Civil durante o segundo governo Vargas, foi professor fundador da Escola Brasileira de Administração Pública (EBPE-FGV) e participou da fundação do Instituto de Estudos Superiores (ISEB), sendo responsável pelo departamento de sociologia da referida instituição de 1955 a 1958. Entrou na vida partidária em 1960 e em 1963 assumiu a cadeira de deputado federal pelo estado da Guanabara.

Sua obra, em grande parte constituída de ensaios voltados à intervenção política na sociedade, abrange uma ampla variedade de temas, como a mortalidade infantil, as questões étnico-raciais, a organização administrativa do Estado, a questão do desenvolvimento nacional, a crítica da intelectualidade brasileira, a interpretação do colonialismo, entre outros ${ }^{2}$.

Maio (1996; 1997) e Guimarães (2003) denominam o grupo de intelectuais ligados ao TEN de intelligentsia negra. Essa palavra foi muito usada entre as décadas de 1940 e 1960. O próprio Guerreiro Ramos definiu o uso que a sua geração fazia desse termo:

A palavra russa intelligentsia, que os sociólogos ùltimamente têm utilizado, vem atender à necessidade de distinguir o intelectual no sentido clássico do têrmo (o escritor, o sábio, o professor) dedicado à criação pura ou ao estudo pelo estudo, daquele tipo de intelectual interessado na produção e difusão de idéias essencialmente enquanto contribuem para a reforma social e para o processo revolucionário (RAMOS, 1961, p. 185).

Karl Mannheim foi um dos intelectuais que refletiram sociologicamente sobre essa categoria. Para ele, a intelligentsia era uma camada intelectual que se esforçava para compreender a dinâmica social da maneira mais ampla possível. Para isso, de um lado, a intelligentsia deveria conhecer e tentar controlar os condicionantes sociais que interferiam na sua própria forma de pensar; de outro, deveria se esforçar para fazer uma síntese dos pontos de vista dos diversos agentes sociais em disputa (MANNHEIM, 1986).

\footnotetext{
2 Para mais informações biográficas o leitor pode consultar as seguintes obras: Nascimento (1950a), Oliveira (1995), Maio (1997; 2015), Barbosa (2004). Já para informações bibliográficas, a obra de Azevêdo (2006) traz o mais completo recenseamento bibliográfico que possuímos no momento.
} 
Quanto ao adjetivo "negra" que acompanha a palavra e o conceito de intelligentsia, o usamos para nos referir a uma ou "um intelectual que, desde determinada época, atribuiu a sua auto-identificação como negro um lugar de enunciação teórica e política" (BARBOSA, 2004, p. 8). Como os comentadores referidos evidenciam, os intelectuais do TEN utilizam-se fartamente desse ponto de vista para realizarem suas enunciações teóricas e práticas.

Desse modo, torna-se compreensível o uso da categoria intelligentsia negra. Primeiro porque tratava-se de um grupo intelectual preocupado em compreender as dinâmicas sociais da maneira mais ampla possível. Segundo porque essa compreensão era militante no sentido de que procurava, por diversos meios, intervir nos processos sociais. Terceiro porque, partindo de um ponto de vista particular, qual seja o de homens e mulheres negras em processo de ascensão social numa sociedade de classes, esse grupo procurou fazer uma síntese global das perspectivas sobre as questões raciais, incorporando e superando o ponto de vista dos intelectuais tradicionais sobre as relações raciais e sobre uma de suas facetas - a ideia de democracia racial.

\section{Contexto dos anos 1940 e 1950}

Os comentadores do tema das relações raciais na obra de Guerreiro Ramos concordam em um ponto fundamental: a democracia racial proposta por esse autor é uma ressignificação ambivalente, feita no interior da intelligentsia negra, do ideário sistematizado por Gilberto Freyre, Arthur Ramos e Donald Pierson acerca da convivência relativamente harmônica das raças no Brasil, atribuída à forma especial da colonização portuguesa baseada na mestiçagem biológica e social (MAIO, 1996; GUIMARÃES, 2003, 2004, 2009; BARBOSA, 2004; CAMPOS, 2015).

Trata-se de uma ressignificação, pois em vez de apontar para o passado, a democracia racial da intelligentsia negra aponta para o presente, numa relação sagital com ele. Isso significa que a democracia racial deixou de ser uma conquista espontânea resultante dos padrões culturais do colonizador português ligados à mestiçagem biológica e social. Ao mesmo tempo, passou a ser concebida como um projeto de planificação democrática da sociedade que se apropriaria da mestiçagem biológica e cultural existente para, colocando-a junto com projetos de inclusão econômica, política e cultural das massas negras, contribuir para efetivar a transição 
de uma sociedade agrária para uma sociedade de mercado na qual a cor de pele não fosse um fator de segregação e discriminação dos grupos sociais. Além disso, a democracia racial, segundo a intelligentsia negra, seria uma forma tanto de canalizar as irracionalidades resultantes dessa transição, quanto de enfrentar os preconceitos e discriminações existentes, em direção à construção de estruturas sociais mais justas.

E essa ressignificação é ambivalente porque não deixa de pactuar com o consenso da existência de relações raciais menos violentas no Brasil em comparação com outros lugares do mundo, sobretudo os EUA, e de considerar o Brasil tanto um laboratório de estudo das relações raciais quanto um modelo a ser seguido por outros países. Porém, nessa ressignificação, a democracia racial deixar de ser uma herança já conquistada para ser um projeto político de orientação da mudança em favor de uma sociedade mais democrática.

Esse pacto epocal em torno da situação racial brasileira fica evidente na seguinte fala de Abdias do Nascimento: "É verdade. Não possuímos, graças a Deus, ódios raciais entre nós. Mas negar o preconceito de côr? Nunca!" (NASCIMENTO, 1950b, p. 5).

Nesse sentido, existem continuidades e rupturas entre o conceito de democracia racial desenvolvido e divulgado, principalmente pelos autores acima mencionados, e aquele apropriado e veiculado pelos movimentos negros dos anos de 1940 e 1950, especialmente por Guerreiro Ramos no interior de sua experiência vivida no TEN. Neste trabalho, para analisar essas continuidades e rupturas, partiremos dos textos de Guerreiro Ramos.

Sabemos que nem a perspectiva de Ramos e nem mesmo a perspectiva do TEN sobre a democracia racial esgotam a maneira como os movimentos negros das décadas de 1940 e 1950 trataram do tema. No entanto, nosso foco de análise recairá exclusivamente sobre esse autor, uma vez que sua compreensão da democracia racial ainda não foi pensada a partir da perspectiva de sua aproximação com a sociologia mannheimiana. Com isso, pretendemos dar uma pequena contribuição ao trabalho maior de traçar o ambiente intelectual dos anos de 1940 e 1950 da perspectiva da intelligentsia negra.

Os textos de Guerreiro Ramos nos quais nos apoiaremos para esta discussão foram escritos entre 1948 e 1956 e foram produtos tanto de uma revisão da literatura sociológica e antropológica sobre o "problema do negro" nas ciências sociais 
brasileiras quanto da convivência e militância de Ramos junto aos e às intelectuais ligados ao TEN ${ }^{3}$.

Como já exposto, o principal elemento que expressa as continuidades entre o projeto de democracia racial dos intelectuais brancos tradicionais e o da intelligentsia negra é a defesa da tese de que as relações raciais no Brasil são singulares se comparadas com o resto do mundo, sobretudo com os Estados Unidos da América. Aqui essas relações seriam mais igualitárias, ao menos no sentido da inexistência de formas legais de discriminação (ainda que isso não implique, para os movimentos negros dos anos de 1940 e 1950, a não existência de forte preconceito e de discriminação de cor) (RAMOS, 1950a).

Já os elementos novos são mais numerosos do que as continuidades. Para autores como Gilberto Freyre (SOUZA, 2000; GUIMARÃES, 2001) e Arthur Ramos (CAMPOS, 2002), a democracia racial era um fato consumado no Brasil. Esse fato se explicaria, segundo esses autores, sobretudo pelo padrão cultural dos colonizadores portugueses que se utilizaram da mestiçagem biológica e cultural como maneira de manter seu domínio sobre as terras descobertas. Já para os movimentos negros do período mencionado, a democracia racial é um programa político que inclui tanto formas de inclusão social e cultural dos negros na ordem capitalista (GUIMARÃES, 2003; 2004) quanto uma terapêutica dos recalques produzidos pelas tensões raciais em brancos e em negros, terapêutica essa feita através do teatro, do psicodrama, do sociodrama e da poesia (QUILOMBO, 1950a, 1950b; RAMOS, 1950b).

Dessa maneira, é a negritude e não a lusitanidade o caminho para a autenticidade nacional do Brasil. A negritude seria uma forma de descolonização das consciências, pois à medida que o sujeito assume a perspectiva singular da negritude, ele percebe como a perspectiva supostamente universal da branquitude permeia o comportamento das pessoas nos países colonizados. A branquitude é então desnaturalizada e mostrada como parte de um processo histórico de dominação, e uma vez compreendida nesses termos, ela pode ser superada a partir de uma perspectiva mais ampla que afirma a condição histórica do sujeito negro como pertencente, em sua singularidade e autenticidade, não apenas à comunidade nacional, mas também à comunidade humana universal (RAMOS, 1995).

\footnotetext{
${ }^{3}$ Para uma contextualização mais detalhada desses textos, o leitor pode consultar Barbosa (2004).
} 
Além do contexto de luta antirracista no qual foi formulada, a democracia racial em Guerreiro Ramos deve ser entendida dentro de um novo paradigma de pesquisa que se consolidava nas ciências sociais brasileiras entre a segunda metade dos anos 1940 e a década de 1950. Trata-se do que podemos chamar de paradigma mannheimiano centrado no uso da ciência como forma de promover mudanças sociais racionalmente controladas. Como mostrou Villas Bôas (2002), esse paradigma se tornou dominante na sociologia dos anos 1950 por meio de autores como Guerreiro Ramos, Florestan Fernandes, Costa Pinto e outros.

Ao contrário de intelectuais como Gilberto Freyre (SOUZA, 2000; GUIMARÃES, 2001), Arthur Ramos (CAMPOS, 2002) e Donald Pierson (SILVA, 2012) que partiram, em maior ou menor medida, de um paradigma culturalista preocupado com os padrões culturais, vistos como parte de uma totalidade de sentido que orientaria as interações entre os grupos raciais, Guerreiro Ramos já ligava a questão racial à ideia de planificação social desde antes de sua entrada no TEN. Inicialmente, procurou conciliar o culturalismo com a perspectiva da planificação social. Em 1946, por exemplo, em uma entrevista à Abdias Nascimento, sobre as relações raciais no Brasil, afirmou Ramos (apud BARBOSA, 2004, p. 41) que:

os dois aspectos da questão (cultura e economia) deve ser, a meu vêr, objeto de medidas gerais, dentre as quais, a mais importante se me afigura ser uma planificação da economia nacional que venha elevar o nível econômico das classes pobres e oferecer oportunidade aos mais aptos sem distinção de côr.

Segundo Ramos, a questão da planificação era central para sua época, pois os princípios do individualismo e da competição próprios à sociedade liberal não mais funcionavam em um contexto de formação de grandes oligopólios econômicos internacionais e de controle da população por meio da propaganda de massa. Nas palavras do autor:

estamos vivendo já numa sociedade planificada. A produção de cultura, o divertimento, a opinião pública, não são esferas livres, mas setores deliberadamente manipulados. Por conseguinte, é incontestável a existência do problema da planificação. [...] O que nos interessa é saber agora que espécie de planificação é necessário realizar, tendo-se em vista as necessidades da democracia (RAMOS, 1946, p. 5). 
Do começo ao fim de sua obra, Guerreiro Ramos manteve um diálogo com Karl Mannheim e se apropriou e modificou o instrumental desse pensador ${ }^{4}$. Em linhas gerais, o ferramental conceitual de Mannheim traz duas questões fundamentais, sendo a primeira a sociologia do conhecimento preocupada em evidenciar os nexos entre pensamento e existência ou, mais especificamente, compreender os elementos inevitavelmente ideológicos de cada forma de pensar. Essa problemática era efetivada pela compreensão da relação entre as formas de pensamento e o lugar ocupado pelos grupos sociais na estrutura social (MANNHEIM, 1986).

A segunda questão era a da planificação democrática entendida, ao mesmo tempo, como uma técnica racional de intervenção na sociedade e como um projeto ético-político de orientação da vida social. Assim, ela envolvia dois tipos de racionalidade, uma técnico-científica voltada para a articulação funcional das estruturas sociais e uma axiológica voltada para a promoção do bem-estar coletivo. Essas duas dimensões da racionalidade atuariam ordenando o fluxo, em grande medida irracional, das vivências e das estruturas sociais (MANNHEIM, 1962).

Dessa maneira, foi no cruzamento de uma agenda de lutas antirracistas e de uma teoria voltada para a orientação da mudança social a partir da busca do bem comum que a democracia racial se transformou num projeto de planificação democrática da sociedade brasileira. Isso é evidente no pensamento de Guerreiro Ramos sobre as relações raciais, pois ele sempre se preocupou com os aspectos pragmáticos e éticos do estudo dessas relações, sobretudo de como esses estudos poderiam ser usados para melhorar as condições de vida da população negra (RAMOS, 1950d; RAMOS, 1995).

\section{A democracia racial enquanto projeto}

Como enfatizou Guimarães (2003; 2004), depois de ser apropriada pelos intelectuais negros, a democracia racial se tornou um projeto político de transformação da sociedade. Convém perguntar: para quem era voltado esse projeto? Esse projeto era voltado para o povo brasileiro. No entanto, a originalidade dessa proposta residia na compreensão de quem constituía esse sujeito político. De maneira bastante enfática, o povo foi apresentado como um sujeito negro em luta pela emancipação

\footnotetext{
${ }^{4} \mathrm{O}$ nome de Mannheim e seus conceitos aparecem em diversas obras do autor, por exemplo, Ramos (1946, 1958, 1961, 1966, 1981, 1995, 2008).
} 
econômica, social e cultural. O lema de Guerreiro Ramos, muito citado pelos comentadores mencionados, era: “o negro é povo, no Brasil” (RAMOS, 1954, p. 63).

Como os comentadores têm destacado, o negro nesse sentido era um "topos lógico" e, poderíamos dizer, existencial, a partir do qual se pode pensar e agir no mundo de forma autêntica. Sendo assim, para Guerreiro Ramos, a posição do negro é tanto um lugar a partir do qual se compreende os pontos nodais que articulam a sociedade brasileira, como um lugar de enunciação de um modo de estar no mundo que se quer autêntico. Nas palavras de Joel Rufino dos Santos (1995, p. 28):

Para Guerreiro Ramos, pois, negro não é uma raça, nem exatamente uma condição fenotípica, mas um topos lógico, instituído simultaneamente pela cor, pela cultura popular nacional, pela consciência de negritude como valor e pela estética social negra. Um indivíduo de qualquer classe, como também um mulato intelectual ou um branco nacionalista (por exemplo) podem ocupar esse lugar e dele, finalmente, vislumbrar o verdadeiro Brasil. Como não lembrar a definição clássica de Clóvis Moura - branco, no Brasil, é o indivíduo que escolheu a cor dos colonizadores para se espelhar, negro o contrário?

Ser negro, para Guerreiro Ramos, significava não apenas reconhecer as particularidades étnicas e culturais que perpassavam o corpo social brasileiro, mas também afirmar essas particularidades como produtoras de um devir, de um novo mundo. Um mundo que, para nascer, deveria destruir a ideologia do branqueamento, a crença implícita dos intelectuais e dos grupos sociais de que tudo associado ao "branco" era superior (RAMOS, 1954).

Mas de quem era esse projeto? No paradigma mannheimiano, os intelectuais eram os mais propensos a elaborarem projetos que teriam em vista a totalidade da sociedade, ou seja, o bem comum. Isso aconteceria porque eles seriam uma camada social relativamente desligada dos vínculos de classe, devido aos seus intensos exercícios de relativização intelectual, que implicavam mudanças constantes na visão de mundo, pensando a sociedade ora de uma posição ora de outra (MANNHEIM, 1986).

No entanto, para Guerreiro Ramos e os membros do TEN, a camada intelectual brasileira não se comprometia com as perspectivas emergentes dos sujeitos negros, pois se mantinha comprometida com as antigas classes dominantes na medida em que faziam estudos folclóricos e culturalistas que supunham que a abolição já havia resolvido todos os problemas da população negra. Portanto, a tarefa 
dos intelectuais seria apenas a de descrever as sobrevivências africanas no novo mundo (RAMOS, 1950c).

Contra essa solução intelectual fantasiosa, haveria uma tradição militante de estudo do negro, centrada na "grande tarefa post-abolicionista" de, nas palavras de Joaquim Nabuco, “'adaptar à liberdade' as massas de côr", ou seja, realizar a "evolução do nível moral, cultural e econômico das massas de côr através de mecanismos de cooperação específicos para o negro" e, ainda, reeducar as camadas brancas para conviverem democraticamente com as camadas pigmentadas (RAMOS, 1950c, p. 2). Guerreiro Ramos enquadrou o TEN e ele próprio como parte dessa tradição militante.

Portanto, podemos argumentar que a democracia racial enquanto técnica social para se atingir o bem comum era, sobretudo, uma formulação de uma intelligentsia negra. Essa intelligentsia era tributária das lutas dos movimentos negros desde a abolição e também das vanguardas intelectuais que se constituíam no mundo, como as vanguardas ligadas à negritude e ao pan-africanismo (BARBOSA, 2004).

Por que essa intelligentsia negra propôs esse projeto de transformação da sociedade? Quais diagnósticos a levaram a isso? Contextualizando sociologicamente o TEN na realidade brasileira, Guerreiro Ramos defendeu a tese de que o grupo seria uma organização fundamental na planificação da sociedade brasileira, uma vez "que é fruto de uma profunda compreensão das peculiaridades do problema do negro no Brasil”. Partindo dessa compreensão, teria encaminhado a solução deste problema da melhor forma possível através da reeducação da "gente negra nos estilos de comportamento da classe média e superior da sociedade brasileira" (RAMOS, 1950d, p. 36-38).

Para justificar essa tese, Ramos estabeleceu um diagnóstico da situação do negro no país realçando o seguinte aspecto: a dificuldade das populações negras em se integrar na sociedade brasileira devido ao fato de que não houve uma planificação social, nem no sentido de combater os efeitos psicológicos da colonização, da escravidão e das frustradas tentativas de ascensão do negro, tampouco no sentido de alterar substancialmente a estrutura social.

Quanto ao primeiro ponto, Ramos destacou que a colonização e a tutela dos povos africanos pelos europeus resultaram numa "profunda ambivalência psicológica" 
que fez o homem de cor "hesitar entre as sobrevivências africanas e os traços culturais representativos do Ocidente" (RAMOS, 1950d, p. 41). Além disso, é preciso considerar que a escravidão é também uma forma ideológica de dominação que moldou a estrutura do caráter dos escravizados no sentido de tornar aceitável a ordem social escravocrata, isto é, no sentido de que "eram, até então, não apenas escravos no corpo; mas psicològicamente escravos" (Ibid, p. 45). Por outro lado, a colonização também moldou o caráter "da população brancóide" no "hábito de servir-se dos homens de côr como instrumento" (Ibid, p. 36).

Diante dessa realidade, incapazes de compreender que a liberdade "é uma situação complexa, dinamizada por fatores psicológicos e sociais numerosos" (RAMOS, 1950d, p. 37), as elites dirigentes tiveram um comportamento idealista utópico, fazendo da liberdade uma condição exclusivamente jurídica:

A condição jurídica de cidadão livre dada ao negro foi um avanço, sem dúvida. Mas um avanço puramente simbólico, abstrato. Sócioculturalmente, aquela condição não se configurou: de um lado porque a estrutura de dominação da sociedade brasileira não se alterou; de outro lado, porque a massa juridicamente liberta estava psicològicamente despreparada para assumir as funções da cidadania (RAMOS, 1950d, p. 37).

Por fim, essa inércia social, fruto da falta de planejamento, agravou a situação psicológica do negro levando-o a um forte ressentimento, pois, embora em aparente igualdade jurídica com o branco, a falta de igualdade econômica e cultural o levava a perder a competição por bens sociais (RAMOS, 1950d, p. 45). Sendo assim, a intelligentsia negra propôs seu projeto de planificação da sociedade, uma vez que tanto a inteligência tradicional quanto as elites foram incapazes de diagnosticar corretamente o problema e ainda mais incapazes de propor soluções efetivas.

Por fim, devemos nos perguntar acerca da legitimidade dessa intelligentsia negra no tal projeto de sociedade. Evidentemente, toda fração de classe ou grupo social possui interesses específicos, por mais que os e as intelectuais busquem uma autonomia relativa em relação à estrutura social. Porém, o que justificava a perspectiva do TEN, aos olhos de Guerreiro Ramos, era que as camadas negras da população estavam, mais do que quaisquer outras, comprometidas com a nova ordem capitalista em criação no Brasil, uma vez que não tinham vínculos com o passado e só tinham, por assim dizer, perspectiva de futuro. 
Quer dizer, na medida em que ocupava as posições mais baixas na antiga ordem social, a população negra veria no processo de urbanização e industrialização que ocorria no Brasil uma chance de ascensão social e a possibilidade de representar novos papéis não subalternos. Por isso, esses grupos eram mais propensos a possuir interesses específicos que poderiam ser generalizados para o conjunto da sociedade (RAMOS, 1995).

\section{A democracia racial como forma de controle das irracionalidades de uma sociedade em transição}

Tendo ficado evidente a partir de quem, para quê, por quê e para quem se colocava a democracia racial como um projeto de planificação, devemos nos perguntar agora que elementos da estrutura social essa planificação procurava alterar.

De maneira geral, sob a perspectiva mannheimiana, todo projeto de planificação da sociedade visa canalizar as forças irracionais que dela se desprendem no sentido da produção de novas formas de sociabilidade. No caso de uma planificação democrática, essas formas de sociabilidade devem, ao mesmo tempo, visar a consolidação dos direitos individuais vindos do liberalismo e também os direitos sociais necessários para a justiça social nas sociedades de massa (MANNHEIM, 1962).

Racionalidade e irracionalidade, na perspectiva de Mannheim, são conceitos relacionais, isto é, não existe nem a racionalidade em si mesma e nem a irracionalidade em si. Sendo assim, algo é racional ou irracional em vista de algum fim ou em vista do encadeamento funcional das condutas. Uma ação pode ser racional ou irracional na medida em que seu sentido direciona-se ou não para um determinado conjunto de valores; em contrapartida, uma ação pode ser racional ou irracional na medida em que se orienta ou não pelo cálculo dos meios necessários para se alcançar alguma finalidade dada de modo exterior à ação social.

Por exemplo, alguém que planeja sua salvação após a morte age de maneira totalmente racional do ponto de vista de seus valores religiosos. Ao mesmo tempo, um suicida que planeja com cuidado todos os passos de sua morte pode agir racionalmente em vista de uma ideologia ateia. Porém, cada um deles age de maneira irracional se visto sob a ótica do outro. Também um soldado que cumpre ordens sem saber sua finalidade age de maneira funcionalmente racional, organizando os meios 
para que o fim de uma determinada ordem seja efetivada, mesmo que ele como subordinado desconheça essa ordem (MANNHEIM, 1962; RAMOS, 2006).

Além disso, é preciso destacar que a irracionalidade não é um elemento puramente negativo, na verdade, na perspectiva de Mannheim, ela é ao mesmo tempo criadora e destruidora. Pode tanto desarticular condutas funcionais como a do soldado, caso ele se recuse a cumprir uma ordem em vista de um valor que é irracional para seus comandantes, quanto pode fundar novas formas de conduta ética. Do mesmo modo, as pulsões das massas gerenciadas pelos novos meios de comunicação podem ser usadas para destruir uma sociedade liberal e construir uma sociedade autoritária (MANNHEIM, 1962).

A partir desse par conceitual racionalidade e irracionalidade, podemos afirmar que o objeto do projeto negro de planificação proposto por Guerreiro Ramos eram as práticas e sentimentos irracionais desencadeados pela transformação de uma sociedade estamental e patrimonialista numa sociedade industrial capitalista e burocrática legal. Para o autor, a destruição de uma ordem social, sobretudo uma escravista de mais de 300 anos, libertava uma série de forças e pulsões reprimidas que poderiam ser usadas para construir uma nova ordem social ou para perverter o futuro fazendo-o retornar para o passado.

No plano ideológico, como já vimos, as elites dirigentes, principalmente aquelas da Primeira República, possuíam respostas idealistas utópicas para as situações nacionais, quer dizer, imitavam instituições estrangeiras como forma de resolver automaticamente os problemas nacionais. No plano prático, porém, isso encobria um interesse específico desse grupo, qual seja, a manutenção dos privilégios de estamento e patrimoniais vindos da ordem social que desabava.

Ora, para Guerreiro Ramos esses interesses eram irracionais do ponto de vista da nova ordem que emergia. Segundo ele, a administração patrimonial nada mais era do que "uma espoliação legitimada pela tradição, em que os cargos públicos são distribuídos como dádivas ou prebendas" (RAMOS, 2008, p. 86-87). Dessa maneira, trata-se de uma organização social pré-moderna, não objetiva e personalista que era incapaz de "distinguir nitidamente a esfera do interesse público e a esfera do interesse privado" (Ibid, p. 86-87).

Do idealismo utópico e do patrimonialismo das elites surgiam obstáculos objetivos e subjetivos à nova ordem social e às classes sociais que a representavam. Entre os obstáculos objetivos encontrava-se a desigualdade econômica e cultural 
excessiva entre brancos e negros e a discriminação de cor. Já entre os obstáculos subjetivos, devidos à importação acrítica de teorias e instituições estrangeiras para simular uma resolução dos nossos problemas sociais, decorria uma profunda colonização mental, uma subserviência aos modelos estrangeiros que causavam prejuízos a brancos e negros (RAMOS, 1995).

No caso das populações negras, os efeitos subjetivos do idealismo utópico e do patrimonialismo das elites eram muito mais profundos porque produtores de amplas cargas de ressentimento. Nesse sentido, Ramos (1950d, p. 44) afirmou que "o ressentimento é uma das matrizes psicológicas mais decisivas do caráter do homem de côr brasileiro", de modo que produz tensões que se manifestam não apenas nas relações entre brancos e negros, mas também nas relações entre "o negro de status inferior contra o negro de status superior, do negro contra o mulato e dêste contra o negro" (Ibid, p. 44). Portanto, o ressentimento impedia a formação de um grupo étnico coeso entre as pessoas de cor de pele escura.

Sendo um dado a existência do ressentimento nas relações cotidianas, a questão sociológica relevante consiste em saber que elementos da estrutura social produziram esse sentimento. Para responder a essa questão, Guerreiro Ramos se utilizou da teoria fenomenológica do ressentimento formulada por Max Scheler, que argumentava que o ressentimento surgia não na relação entre grupos de status diferentes, mas sim entre grupos de status formalmente iguais. Em vista disso, afirmou Scheler (2012, p. 53-54) que:

O peso externo do ressentimento precisa por isso possuir uma sociedade, na qual [...] a igualdade social de direito estabelecida formalmente caminhe lado a lado com uma enorme diferença do poder de fato, da possessão de fato, e da formação e conformação de fato: onde todos possuem o 'direito' de se comparar com todos, sem 'realmente' possuírem o 'poder de fato para se comparar'. Aqui está, [...] já por meio da estrutura da sociedade, uma poderosa carga para o ressentimento no corpo social.

Apoiado nessa teoria, Ramos (1950d, p. 44) defendeu a tese de que o ressentimento dos negros e mulatos "é um precipitado emocional da estrutura da sociedade republicana brasileira". O que é interessante nesta tese é que ela nem culpa os grupos oprimidos pelo ressentimento de que são possivelmente portadores, nem coloca a causa no escravismo, pois é a estrutura social pós-abolição que produzia o ressentimento nas populações afro-brasileiras. 
Como isso ocorria? De maneira geral, no interior da sociedade escravista, as relações entre senhor e escravo eram legitimadas por uma ideologia religiosa quietista, de modo que ao próprio escravo essa estrutura social "parecia um esquema definitivo", onde as posições sociais eram sancionadas pelo sagrado e pela Natureza. Poucos escravos tinham os recursos simbólicos necessários para contestar essa ordem social, de modo que "desenvolviam atitudes, sentimentos, lealdades e crenças que se ajustavam ao seu status inferior" (RAMOS, 1950d, p. 44).

Com a abolição da escravatura, a igualdade formal forçou o negro a adentrar em uma nova forma de competição social em que as posições não são fixas, na qual o desejo de ascender força as pessoas a mudarem constantemente de posições. Nessas condições, "o negro deixou de ser um quietista para ser um 'aquisitivo'. Passou a ser 'igual' ao branco, e quando experimentou sê-lo sentiu sua própria impotência" (RAMOS, 1950d, p. 45). Daí a origem do seu ressentimento: o desejo de ascender diante da impossibilidade de fazê-lo. E esta impossibilidade se radicava exatamente na extrema desigualdade econômica e social que acompanhava aquela igualdade formal. Disto decorria que a questão da ascensão social e econômica se constituía no problema essencial do "negro".

Tendo em vista o idealismo utópico das elites pós-abolição, a persistência da prática patrimonialista e o ressentimento gerado por ambos, vemos que a democracia racial jamais é um fato para Guerreiro Ramos, pelo contrário, é uma política pública que precisa ser realizada na prática e de maneira urgente para se evitar o esfacelamento do social pelas irracionalidades que surgem da persistência de elementos de uma ordem escravocrata numa sociedade de mercado. Nesse sentido, Guerreiro Ramos alerta que aquele fluxo de ressentimento gerado pela nova ordem republicana é "da ordem daquela dinamite psíquica que na Revolução Francesa impulsionou a plebe contra a nobreza espúria” (RAMOS, 1950d, p. 44).

\section{A democracia racial enquanto técnica de planificação}

Partindo de um raciocínio preocupado com a interdependência dos fenômenos sociais, já em 1946, como vimos, Ramos indicou os contornos gerais da resolução dos problemas dos descendentes de pessoas escravizadas. Para ele, o problema envolvia duas dimensões. De um lado, "uma planificação da economia nacional que venha elevar o nível econômico das classes pobres e oferecer 
oportunidade aos mais aptos sem distinção de côr" e, de outro lado, a criação e o fomento de associações culturais negras com intuitos artísticos e de auxílio mútuo (RAMOS apud BARBOSA, 2004, p. 41). Anos mais tarde, Ramos defenderia a mesma ideia da planificação afirmando que "o processo de libertação da gente de côr precisa ser submetido a uma técnica" (RAMOS, 1950d, p. 37).

No projeto de Ramos, sociedade civil e o Estado desempenhariam papéis complementares e essenciais. O Estado deveria criar "na sociedade brasileira mecanismos integrativos de capilaridade social capazes de dar função e posição adequada aos elementos da massa de côr que se adestrem nos estilos de nossas classes dominantes" (RAMOS, 1950d, p. 37). De outra parte, associações como o TEN produziriam a reeducação social, cultural e artística das massas para as novas condições sociais e econômicas em produção. Caso esses dois lados não caminhassem juntos, Ramos previa a criação de "situações marginais dentro da sociedade" (p. 37) que agravariam as tensões sociais.

Para a realização dessa planificação, que canalizaria os conflitos e os ressentimentos para fins socialmente produtivos de modo a constituir uma democracia racial no país, seria necessário que "os poderosos" despertassem "de sua indiferença e de seu egoísmo" e se aliassem às associações da sociedade civil, reconhecendo "aquilo que o gênio e a vontade do T.E.N oferecem à sociedade brasileira de mais singularmente construtor" (RAMOS, 1950d, p. 46).

Portanto, enquanto o Estado deveria ser responsável pelo desenvolvimento da estrutura social de modo a absorver cada vez mais as pessoas negras nas posições médias e superiores, o TEN tomaria parte das dimensões psíquicas que essa integração envolveria. Para poder atuar dessa forma, os membros do TEN formavam uma espécie de intelectuais orgânicos, pois esforçavam-se por manter-se na vanguarda do debate acerca das relações étnicas no Brasil ao mesmo empo em que procuravam estabelecer laços com os movimentos negros e com as vivências das pessoas negras envolvidas na competição com os brancos por melhores posições sociais.

Essa dupla tarefa constituía o cerne do projeto de planificação do TEN. Ela corresponde bem à categoria de intelectuais orgânicos segundo a qual esse grupo tem que estar "na vanguarda do trabalho intelectual [...] conhecer bem e profundamente" e também "não pode subtrair-se da responsabilidade de transmissão 
dessas ideias, desse conhecimento, através da função intelectual, aos que não pertenciam profissionalmente, a classe dos intelectuais" (HALL, 2003, p. 207). Isso fica evidente nesta afirmação de Ramos: "o Teatro Experimental do Negro é um movimento vanguardista de elevação cultural e econômica dos homens de côr, em cujos quadros se processa a elaboração consciente da ideologia tradicional do Brasil com respeito a relações de raça" (RAMOS, 1950b, p. 11).

Como o TEN realizaria essa "elevação cultural e econômica dos homens de côr" (RAMOS, 1949b, p. 7)? Através do desenvolvimento de uma série de instituições sociais ligadas direta ou indiretamente ao teatro. Essa política teria sido produto de uma "poderosa intuição artística e sociológica" de Abdias do Nascimento, que teria compreendido que podia "pelo teatro adestrar os homens de côr nos estilos de comportamento de classe média e superior" (Ibid, p. 7). A função social do TEN seria a de, por meio de um "processo catártico", constituir "um campo de polaridade psicológica, onde o homem encontra oportunidade de eliminar as tensões e os seus recalques" (Ibid, p. 7).

Esse "campo de polaridade psicológica" constituía-se, sobretudo, de uma série de iniciativas e instituições criadas pelo TEN (concursos de beleza, cursos de alfabetização, conferências, espetáculos, jornais, congressos, debates públicos e terapias de grupo) que serviam para a expressão de temas relacionados aos problemas sociais, econômicos e culturais das pessoas negras - ainda que os brancos também participassem em muitas dessas instituições. Nelas as tensões sociais deixariam de ser recalcadas e seriam discutidas em público, muitas vezes confrontadas pela argumentação, por histórias pessoais e por catarses artísticas.

Assim, essas instituições favoreciam, de um lado, a assimilação pelos negros dos padrões de argumentação e de organização do pensamento próprio aos grupos intelectuais e acadêmicos e, de outro, enriqueceriam esses grupos intelectuais com as vivências das situações práticas que enfrentavam os negros de grupos populares e com as reflexões que produziam sobre a sua prática cotidiana. Com isso, elas eram, concomitantemente, ressocializadoras e terapêuticas.

Dessa forma, o diferencial do TEN seria utilizar-se primariamente do teatro e de práticas correlatas para, ao mesmo tempo, diminuir as tensões psicológicas geradas pelas relações étnicas no Brasil e possibilitar condições para a apropriação pelos negros dos padrões de comportamento das classes média e superior. A catarse 
teatral seria a prática primordial nesse processo, abrindo caminho para que a arte transformasse "a luta de classes num processo de cooperação" (RAMOS, 1949, p. 7).

Desse modo, Ramos enfatizava a distância do TEN de práticas que poderiam ser associadas ao ressentimento, na medida em que o grupo se voltava à afirmação de valores positivos da cultura ocidental, não para meramente negá-los, mas sim abrir espaço para a subjetividade negra. Pelo fato de ser socializada tanto dentro das tradições africanas e de seus desenvolvimentos no Brasil quanto dos padrões culturais ocidentais, essa subjetividade negra seria portadora de uma cultura ambivalente capaz de transformar a civilização ocidental, renovando-a com valores advindos da experiência sublimada da diáspora (RAMOS, 1950d).

\section{Considerações finais}

Nossa intenção é ter mostrado a existência de um projeto político de transformação da sociedade a partir da perspectiva do "povo negro" no Brasil. Por meio de uma análise da coerência interna desse projeto, acreditamos ter evidenciado que ele era formulado por uma intelligentsia negra da qual Ramos era parte. Essa intelligentsia formulava sua teoria a partir da perspectiva do povo negro em busca da ascensão social numa ordem capitalista e procurava meios para que essa ascensão se efetivasse com justiça social e com o mínimo de traumas psicológicos.

Sendo assim, defendia a necessidade de o Estado produzir o desenvolvimento econômico que, por sua vez, abriria novas posições na estrutura social para a população negra. Ao mesmo tempo, instituições culturais como o TEN trabalhariam através da arte e da ciência (congressos, sociodrama, psicodrama, poesia, teatro) para que a integração psicológica do povo negro ocorresse com o mínimo de traumas.

Esse projeto se apoiou num diagnóstico da estrutura social brasileira e dos seus efeitos psicológicos no povo, o qual percebia os anos de 1940 e 1950 como um período de transição de uma ordem social colonial para uma ordem social capitalista. Nesse cenário, as elites tradicionais mostraram sua incapacidade de resolver o problema da integração do negro na sociedade de classes, logo, uma nova força política deveria assumir o controle dos processos de planificação social. Inserida 
nessa nova força política, a intelligentsia negra teria um lugar sobressalente, pois teorizava a partir do ponto de vista popular.

Em contrapartida, essa intelligentsia reconhecia a necessidade de canalizar os ressentimentos gerados pelo idealismo utópico das elites que deu igualdade de direitos ao povo negro, mas não deu condições de uma igualdade de fato. Somente com condições justas de competição esse ressentimento poderia ser usado como força motriz no processo de ascensão de parte da população negra.

Apresentamos ainda a ideia de que através de instituições como o teatro, os concursos de beleza, a literatura, a antropologia, as terapias de grupo, a produção de revistas, entre outras, o TEN produziu ações concretas para intervir racionalmente nas forças e sentimentos irracionais desencadeados no processo de transição de uma ordem patrimonial escravocrata para uma ordem capitalista. Por meio dessas instituições, o TEN buscava manter condições de sanidade psíquica para a população negra do país, envolvida numa competição desigual por oportunidades sociais.

O essencial do projeto de democracia racial proposto por Guerreiro Ramos consistia na afirmação de que sem o desenvolvimento e a diversificação da estrutura social por meio da aceleração do processo capitalista, sem políticas públicas e culturais que garantissem condições justas de competição por posições na estrutura social e sem um projeto cultural de valorização estética e subjetiva da pessoa negra, seria impossível uma democracia racial no país. Nesse sentido, caso não fosse um projeto realista de transformação social, a democracia racial seria uma ideologia ou uma utopia e, assim, necessariamente, serviria para encobrir os interesses vindos do passado ou as potencialidades realmente presentes na estrutura social brasileira.

Por fim, gostaríamos de apontar que essas ações concretas, inseridas num projeto amplo de transformação da sociedade, eram o resultado cumulativo das lutas dos negros não apenas no Brasil, como também em todo o Ocidente, tal qual foi evidenciado por trabalhos como os de Barbosa $(2004,2006,2013)$. No entanto, essas ações e esse projeto são muito pouco estudados, e diversas investigações poderiam ser feitas acerca do quão efetivo foi esse projeto e porque ele perdeu força nos anos de 1950. Talvez na reatualização de projetos como o tratado neste trabalho, possamos encontrar algumas saídas para os dilemas que vivemos no presente. 


\section{Aprovado para publicação em 19 de dezembro de 2020.}

\section{Referências}

ANDREWS, George Reid. Visões afro-americanas sobre o Brasil, 1900-200. Rev. Ciências Sociais, v. 48, n. 2, p. 20-52, 2017.

AZEVÊDO, Ariston. A Sociologia Antropocêntrica de Alberto Guerreiro Ramos. 2006. 267 f. Tese (Doutorado). Universidade Federal de Santa Catarina, Florianópolis, 2006.

BARBOSA, Muryatan Santana. Guerreiro Ramos e o personalismo negro. 2004. 296 f. Dissertação (Mestrado). Curso de Mestrado em Sociologia, Universidade de São Paulo, São Paulo, 2004.

BARBOSA, Muryatan Santana. Guerreiro Ramos: o personalismo negro. Tempo Social, v. 18, n. 6, p. 217-228, 2006.

BARBOSA, Muryatan Santana. O TEN e a negritude francófona no Brasil. Rev. bras. Ci. Soc., São Paulo, v. 28, n. 81, p. 171-184, fev. 2013. Disponível em: http://www.scielo.br/scielo.php?script=sci_arttext\&pid=S0102-

$69092013000100011 \&$ Ing=en\&nrm=iso. Acesso em: 29 nov. 2020.

CAMPOS, Maria José. Arthur Ramos: Luz e sombra na antropologia brasileira: uma versão da democracia racial no Brasil nas décadas de 1930 e 1940. 2002. Dissertação (Mestrado). Faculdade de Filosofia Ciência e Letras, Universidade de São Paulo, São Paulo, 2002.

CAMPOS, Luiz Augusto. O negro é povo no Brasil: afirmação da negritude e democracia racial em Alberto Guerreiro Ramos (1948-1955). Caderno CRH, Salvador, v. 28, n. 73, p.91-110, abr. 2015.

CARVALHO, Layla Daniele Pedreira de. O equilíbrio de antagonismos e o Niger Sum: relações raciais em Gilberto Freyre e Guerreiro Ramos. 2008. Dissertação (Mestrado). Pós-Graduação em Sociologia, Universidade de Brasília, Brasília, 2008.

GUIMARÃES, Antônio Sérgio Alfredo. Democracia racial: o ideal, o pacto e o mito. Novos Estudos Cebrap, São Paulo, n. 61, p. 147-162, 2001.

GUIMARÃES, Antônio Sérgio Alfredo. Intelectuais negros e modernidade no Brasil. Working Paper CBS-52-04, Centre for Brazilian Studies, Oxford University, 2003.

GUIMARÃES, Antônio Sérgio Alfredo. Intelectuais negros e formas de integração nacional. Estudos avançados, v. 18, n.50, p. 271-284, 2004.

GUIMARÃES, Antônio Sérgio Alfredo. Racismo e antirracismo no Brasil. 3. ed. São Paulo: Editora 34, 2009.

HALL, Stuart. Da diáspora: identidade e mediações culturais. Belo Horizonte: Editora da UFMG; Brasília: Representação da UNESCO no Brasil, 2003. 
HASENBALG, Carlos. Discriminação e desigualdades raciais no Brasil. Rio de Janeiro: Graal, 1979.

MACEDO, Márcio José de. Abdias do Nascimento: a trajetória de um negro revoltado (1914-1968). 2005. Dissertação (Mestrado). Departamento de Sociologia da Faculdade de Filosofia, Letras e Ciências Humanas da Universidade de São Paulo (USP), São Paulo, 2005.

MAIO, Marcos Chor. A questão racial no pensamento de Guerreiro Ramos. In: MAIO, Marcos Chor, SANTOS, Ricardo Ventura (org.). Raça, ciência e sociedade. Rio de Janeiro: Editora FIOCRUZ; CCBB, 1996. p.179-193.

MAIO, Marcos Chor. Uma polêmica esquecida: Costa Pinto, Guerreiro Ramos e o tema das relações raciais. Dados, Rio de Janeiro, v. 40, n. 1, p. 127-163, 1997. Disponível em: http://www.scielo.br/scielo.php?script=sci_arttext\&pid=S001152581997000100006\&lng=en\&nrm=iso. Acesso em: 12 nov. 2020.

MAIO, Marcos Chor. Cor, intelectuais e nação na sociologia de Guerreiro Ramos. Cad. EBAPE.BR, Rio de Janeiro, v. 13, n. spe, p. 605-630, set. 2015. Disponível em: http://www.scielo.br/scielo.php?script=sci_arttext\&pid=S1679-

$39512015000700007 \&$ Ing=en\&nrm=iso. Ācesso em: 18 nov. 2020.

MANNHEIM, Karl. Ideologia e utopia. 4. ed. Rio de Janeiro: Guanabara, 1986.

MANNHEIM, Karl. O homem e a sociedade: estudos sôbre a estrutura social moderna. Rio de Janeiro: Zahar, 1962.

NASCIMENTO, A. Cartaz: Guerreiro Ramos. Quilombo, v. 2, n. 9, p. 2, 1950a.

NASCIMENTO, Abdias. Convite ao encontro. Quilombo, v. 2, n. 9, p. 5, 1950b.

NASCIMENTO, Abdias. Teatro Experimental do Negro: trajetória e reflexões. Estudos Avançados, v. 18, n. 50, 2004.

NASCIMENTO, Elisa Larkin (org.). Guerreiras de natureza: mulher negra, religiosidade e ambiente. São Paulo: Selo Negro, 2014.

OLIVEIRA, Lucia Lippi. A sociologia do guerreiro. Rio de Janeiro: Editora da UFRJ, 1995.

QUILOMBO. Rio de Janeiro, n. 6, 1950a.

QUILOMBO. Rio de Janeiro, n. 10, $1950 \mathrm{~b}$.

RAMOS, Alberto Guerreiro. Notas sôbre planificação social. Revista do Serviço Público, Rio de Janeiro, v. 4, n. 3, p. 163-166, dez. 1946. Disponível em: http://www.crarj.adm.br/publicacoes/DASP/alberto_guerreiro/notas_sobre_planificac ao_social/. Acesso em: 23 nov. 2020.

RAMOS, Alberto Guerreiro. Uma experiência de grupoterapia. Quilombo, Rio de Janeiro, v. 1, n. 4, p.7-7, jul. 1949. 
RAMOS, Alberto Guerreiro. Apresentação da negritude. Quilombo, Rio de Janeiro, v. 2, n. 6, jul. 1950a.

RAMOS, Alberto Guerreiro. Teoria e prática do psicodrama. Quilombo, Rio de Janeiro, v. 1 , n. 6 , p. $6-7$, fev. 1950 b.

RAMOS, Alberto Guerreiro. Os estudos sôbre o negro brasileiro. A Manhã, Rio de Janeiro, p. 1-2, 10 dez. 1950c.

RAMOS, Alberto Guerreiro. O negro no Brasil e um exame de consciência. In: RAMOS, Alberto Guerreiro; NASCIMENTO, Abdias do; RIBEIRO, Joaquim; FISCHLOWITZ, Estanislau. Relações de raça no Brasil. Rio de Janeiro: Quilombo, 1950d. p. 35-46.

RAMOS, Alberto Guerreiro. O problema do negro na sociologia brasileira. Cadernos do Nosso Tempo, Rio de Janeiro, v. 2, n. 2, p.189-220, jan./jun. 1954.

RAMOS, Alberto Guerreiro. Gilberto Freyre ou a obsolência. Para todos, Rio-São Paulo, n. 11, p. 14, out. 1956a.

RAMOS, Alberto Guerreiro. À propos de Gilberto Freyre. Arguments, Paris, n. 1, p. 2225, 1956b. Disponível em: https://archivesautonomies.org/IMG/pdf/inclassables/arguments/arguments-n01.pdf. Acesso em: 15 maio 2020.

RAMOS, Alberto Guerreiro. A redução sociológica. Rio de Janeiro: Instituto Superior de Estudos Brasileiros, 1958.

RAMOS, Alberto Guerreiro. A crise do poder no Brasil. Rio de Janeiro: Zahar Editôres, 1961.

RAMOS, Alberto Guerreiro. Administração e estratégia de desenvolvimento: elementos de uma sociologia especial da administração. Rio de Janeiro: Fgv, 1966.

RAMOS, Alberto Guerreiro. A nova ciência das organizações: uma reconceituação da riqueza das nações. Rio de Janeiro: FGV, 1981.

RAMOS, Guerreiro. A sociologia de Max Weber: sua importância para a teoria e a prática da administração. Revista do Serviço Público, Brasília, DF, v. 52, n. 2, p.267282, jun. 2006. Disponível em: http://repositorio.enap.gov.br/handle/1/1343. Acesso em: 19 nov. 2020.

RAMOS, Alberto Guerreiro. Uma introdução ao histórico da organização racional do trabalho: ensaio de sociologia do conhecimento. Republicação. Brasília: Conselho Federal de Administração, 2008.

RAMOS, Alberto Guerreiro. Introdução crítica à sociologia brasileira. 2. ed. Rio de Janeiro: Editora da UFRJ, 1995.

SANTOS, Joel Rufino dos. O negro como lugar. In: RAMOS, Guerreiro. Introdução crítica à sociologia brasileira. 2. ed. Rio de Janeiro: Editora da UFRJ, 1995. p. 19-29. 
SCHELER, Max. O ressentimento na construção das morais. In: SCHERLER, Max. Da reviravolta dos valores: ensaios e artigos. 2. ed. Petrópolis, RJ: Vozes; Bragança Paulista, SP: Editora Universitária, 2012. p. 43-182.

SILVA, Isabela Oliveira Pereira da. De Chicago a São Paulo: Donald Pierson no mapa das ciências sociais (1930-1950). 2012. Tese (Doutorado). Faculdade de Filosofia, Letras e Ciências Humanas da Universidade de São Paulo, São Paulo, 2012.

SKIDMORE, Thomas E. Preto no branco: raça e nacionalidade no pensamento brasileiro. Rio de Janeiro: Paz e Terra, 1976.

SOUZA, Jessé. Democracia racial e multiculturalismo: ambivalente singularidade cultural brasileira. Estud. afro-asiát., Rio de Janeiro, n. 38, p. 135-155, dez. 2000. Disponível em: http://www.scielo.br/scielo.php?script=sci_arttext\&pid=S0101546X2000000200007\&lng=pt\&nrm=iso. Acesso em: 19 nov. $202 \overline{0}$.

VILLAS BÔAS, Glaucia. Os portadores da síntese: sobre a recepção de Karl Mannheim. Cadernos CERU, São Paulo, v. 13, p. 125-143, jan. 2002. Disponível em: https://www.revistas.usp.br/ceru/article/view/75281. Acesso em: 15 nov. 2020. 